\title{
REESTABLISHMENT OF A SCINCID LOST SINCE 1837
}

\author{
Chapman Grant, Major, U. S. Army \\ Mabuya semitaeniatus (Wiegmann)
}

Euprepes semitaeniatus, Wiegmann, Arch. f. Nat. p. 135_____ 1837 Mabuya sloanii (Daudin) Stejneger, Report U. S. Nat. Mus.

for 1902 p. 610___-_._. 1904 Mabuya sloanii (Daudin) Schmidt, N. Y. Acad. Sci. Vol. 10, Pt. 1, p. 121 Mabuya sloanii (Daudin) Barbour, Zoologica, p. 105 The type is No. 5290 in the Berlin Nat. Hist. Museum.

Wiegmann described Euprepes (Mabuya) semitaeniatus in 1837 from an unknown source. Since that time the few specimens obtained have been grouped with $M$. sloanii (Daudin) as synonymous. The difference in coloration was noted by Stejneger and Schmidt, but sufficient material was not at hand to prove the specific differences.

My collection contains six Mabuyas from Porto Rico which agree with Schmidt, 1928 Fig. $38 \mathrm{~A}$ in color and pattern. Counting his specimens this makes 8 from Porto Rico which are clearly $M$. sloanii.

I have just taken a series of 27 specimens from Culebra Island and the adjoining SW key, known as Louis Pena Key, and 35 from Mona Island. All agree exactly in color and pattern with Schmidt, 1928, Fig. 38 B in having the narrow median light line. This brings the total to 62 which agree in coloration.

My Porto Rico specimens have the back a uniform brown. Most of those from Culebra and Mona islands have a series of marks consisting of the center third segment of the scale being almost black. These marked scales spread from the lateral and dorsal dark bands, forming broken lines of triangular dots, more or less numerous along the back and clear down the tail in some specimens. The median line on the head is as light as the white dorso-lateral line in some from Mona and Culebra islands, but much darker in those from Porto Rico. The dorso-lateral light lines on the Porto Rico specimens are irridescent bluish along the body, whereas they are cream colored in the Culebra and Mona islands specimens.

I kept one female alive and she bore four young in from 36 to 48 hours between the first and last. The mother and young take insects, crickets, cockroaches and sowbugs. The young are colored like the adult except the tail which is white at the tip and lavendar nearly 
to the body. This is reminiscent of the "blue tailed" skink of the middle west United States, Eumeces guttulatus, which it remained for Burt, 1928 to show was the young of $E$. obsoletus (B. \& G.)

On Culebra and Mona islands the Mabuya or "Lucia" as the natives call it, is found among Opuntia repens Bello, at sea level just above the beaches and among: the rocks on the hills. Some inhabit houses. They are tame, but show strength when held in the fingers. They make no attempt to bite.

In discussing $M$. spilonota, Wiegmann, from Jamaica and $M$. sloanii (Daudin); Stejneger 1904. p. 609, states: "Thus, separated supranasals and three pairs of nuchals seem to predominate in $M$. spilonota, while supranasals in contact and two nuchals belong to the eastern form". (M. sloanii and $M$. semitaeniatus.) These observations are borne out by my series of which 43 have the supranasals in contact and 18 only have them separated. Of nuchals, 2 have $1-1 ; 15$ have $2-1 ; 31$ have $2-2 ; 9$ have $2-3 ; 2$ have $3-3$; 1 has $1-6$ and two are mangled.

I notice that most specimens, and especially the young, have a pronounced transluscent pineal spot, sometimes pit, at the posterior part of the interparietal scale. One freak specimen has two small scales at this point which resemble occipitals.

The separation of $M$. semitueniatus from $M$. sloanii rests on the constant color and pattern difference. The specimens in my collection I believe reestablish the name Mabuya semitaeniatus (Wiegmann) for the Culebra and Mona island species.

Photograph by Captain Frederick V. Edgerton, U. S. A.

\section{Explanation of Plate XXV}

Mabuya semitaeniatus Wiegmann.

Note head pattern.

Four young were born in eaptivity. Their tails are lavendar with white tips.

$11 / 3 \times$ natural size.

Photo by Capt. Frederick V. Edgerton, U. S. A. 


\section{PLATE XXV.}

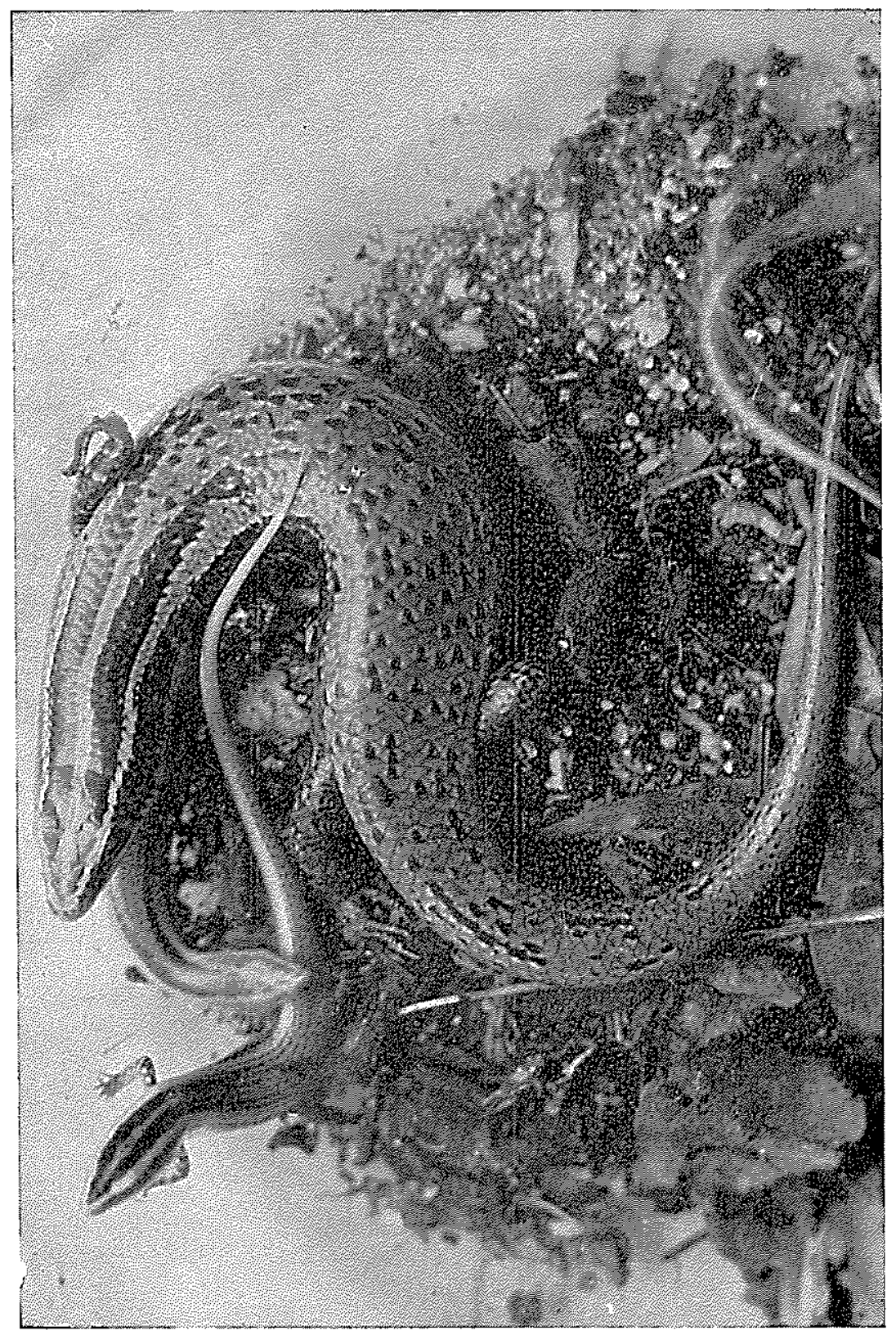

